\title{
Analysis on The Role of Rehabilitation Centers and its Effects on The Reducation of Drug Addiction in Quetta City
}

Z. Unnisa (Zaib Unnisa)', A. Gul (Ayesha Gul)², A. Naz (Arab Naz)³

${ }^{1}$ M. Phil Scholar Dept. of Sociology, SBK Women's U. Quetta.

Original Article Balochistan, Pakistan

2 Assistant Professor Social Work Department, SBK Women's University Quetta. Balochistan, Pakistan

${ }^{3}$ Prof, Sociology Department, University of Malakand. Khyber Pakhtunkhwa, Pakistan

\section{E-mail address:}

gul_aisha@hotmail.com

\section{Reprint address:}

Ayesha Gul

Social Work Dept. SBKWU University Balochistan

Bawrery Road, Quetta

Balochistan

Pakistan

Source: Clinical Social Work and Health Intervention

Pages: $48-58$

Volume: 10

Cited references: 12

Issue: 1

\section{Reviewers:}

George Benca

House of Family, Phnom Penh, Cambodia

Vitalis Okoth

MPC, Nairobi, Kenya

\section{Key words:}

Narcotics. Detoxification. Rehabilitation. Drug Addict. Treatment. Drug trafficking. Drug Abuse. Reduction.

\section{Publisher:}

International Society of Applied Preventive Medicine i-gap

CSWHI 2019; 10(1): 48 - 58; DOI 10.22359/cswhi_10_1_08 @ 2019 Clinical Social Work and Health Intervention

\section{Abstract:}

Narcotics have become a global problem and have assumed to be progressively serious issue internationally. World Health Organization (WHO) defined drugs as "any substance when consumed by the living 
organism may alter one or more functions. The treatment and rehabil-itation of drug addicts is long and painful journey from drug dependency to a healthy and drug-free lifestyle. Rehabilitation programmers are extremely costly and demand highly motivated people to take care of drug addicts in any given circumstances. In Pakistan, the majority of existing treatment and rehabilitation facilities provide detoxification services. The Detoxification and Rehabilitation Complex Quetta was established in 26 March 2009. The current study is qualitative in nature that seeks to find out the effects in reduction for drug addicts in Quetta City. The data was gathered by conducting interviews and Focus Group Discussion (FGD) among administrative staff, nurses and the family members of the rehabilitation center and the family members of addicts. Using statistical tools of Microsoft Office (Excel) the data derived from the interviews was analyzed. The result of the study indicated that problems like: lack of community support; easily available psychoactive drugs in the society; partial number of drug rehabilitation centers; lack of medicines in the rehabs; lack of doctors; etc. are the key factors that hinder the treatment process. A variety of supportive services for enhancing the rehabilitation process were found to be in practice These trainings include life skills training; job counseling; skills like shoe making, tailoring, electrical work; etc. Being an Islamic state, counseling through religious scholars is a common practice as to make the addicts realize and get ready to give up the drugs. The present study established that the medicinal drugs used in the treatment did affect the treat-ment. Most of the enrolled clients get fully well after completion of the treatment. The Detox and Rehab has been in action since 2009 and located in the outskirts of Quetta (Eastern-by-pass) and getting popularity among the masses for its treating and rehabilitation purposes.

\section{Background of the Study}

Narcotics have become a global problem and have assumed to be a progressively concerning issue internationally. Drug abuse is becoming a serious threat to developed and developing countries (Collins, 2012). Extensive efforts are being made by governments to reduce the illegal production, marketing and supply of all type of drugs. The United Nations has taken in account a manuscript demanding reduction where a complete policy to suppress the requirement of substances of drug abuse was started. Core principles were planned which would be combined to sponsor co-operation among all relevant bodies, and would include an extensive range of suitable interventions and encourage healthy and social developed members, their families and countries. It must decrease the unpleasant outcomes of drug use for the members of the society (White W. L, 1998).

\section{A Brief History of Drug Use in Pakistan}

Pakistan has faced the crisis of drug use since it came into existence. The country faces the largest heroin use market in the Southeast Asian area. While the whole area 
is suffering from drug trafficking in South Asia, Pakistan has become its most horrible victim. Opium and poppy have often been in cultivation in most parts of Pakistan. Opium was sold in stores authorized for the first part of the decade. After independence in 1947, the government followed the same laws as in the late $19^{\text {th }}$ century, when the "Hadoop" law was officially announced. The law prohibited the cultivation, manufacture, trade and exercise of drugs in Pakistan, which caused the closure of the legal drug shops. However, illegal and ease of availability of drugs continued. By the start of 1980, heroine drugs use spread outside the country. Pakistan emerged as an important exporter of drugs like heroin in the 1980s, after an immense arrival of Afghan refugees. The main outcome of this flood was a major rise in use of domestic heroin in the country. In comparison to other drug addicts, heroin addicts rose from $7.5 \%$ in 1983 to a shocking $51 \%$ by the end of 1993 . Since then, the use of heroin has reached epidemic proportions. Its size in Pakistan affected almost all socio-economic groups. Like all other human development evils, the crisis of drug abuse affects the most helpless; most of the drug addicts in Pakistan are from the poorest sections of society (Altaf A Shah et al., 2007).

\section{The Purpose of Study}

The current study was designed to identify role of rehabilitation center in terms reducing the number of drug addicts. The aim was to get opinions of the staff offering management in the Rehab (Quetta) regarding their viewpoints on the factors that hinder the treatment process, reducing the number of drug abusers.

\section{Objectives}

The core objectives of the study are:

Analyses of the role of a rehabilitation center for drug addicts.
Find out the effects of rehabilitation center in the reduction of drug addiction in the society.

Recommend how the role of a rehabilitation center can be improved to reduce the addiction problem.

\section{Research Questions}

The current study specially attempts to answer the following phrases.

Background Information of the Respondents and their qualifications and experience.

Major factors hampering treatment processes in rehabilitation.

Supportive services for clients to enhance the process of drug abuse rehabilitation.

Perception of employees on the nature of drugs and treatments offered.

\section{The Research Design}

This study is based on the qualitative in nature that seeks to find out the effects in reduction for drug addicts in Quetta City. Data were gathered by conducting interviews and Focus Group Discussion among administrative staff, nurses and family members of the rehabilitation center and family members of addicts.

\section{Participants}

In this study the family members and the administrative staff and nurses from the rehabilitation center in Quetta City were selected. The participants were from different areas; administrative staff was 5; 3 nurses; 4 family members for Focus Group Discussion.

\section{Data Collection Tool}

This study was conducted to measure the effects in reduction of drug addicts in Quetta City. The first step in the data collection process was to obtain permission from the administer of detoxification and rehabilitation 
center located in eastern by pass. A research visit was made to the Detoxification and Rehabilitation Center in Eastern Bypass Quetta. For getting information, a qualitative research technique was conducted with the administrative staff, nurses and family numbers of the addicts. In-depth interviews and focus group discussion (FGD) were used as data collection tools in this study. After receiving permission from the Administer, interviews were taken with the administrative staff and the nurses. FGD (focus Group Discussion) was also conducted among the family members of government rehabilitation and a private rehabilitation center. The core themes of the interview and discussion are as follow:

The proposed study is a qualitative research.

The proposed study is a case study as it is an analysis on a Rehabilitation Center situated in Quetta City.

Since the proposed study is a qualitative research, detailed interviews with the management of the rehabilitation center were conducted. An interview protocol will be developed to guide the interview process.

The sample of the proposed study is the higher and middle management employees of the rehabilitation center.

The total number of interviewees will be five.

Two employees are from senior management and three are middle management of the rehabilitation center.

The data is collected from the interviews and from publications, reports and analysis of rehabilitation center to analyses the role of the rehabilitation center and its effects on reduction of drug addiction in Quetta City.

\section{Significance of the Study}

This current study was designed to highlight the role of the rehabilitation center and pinpoint the factors that might hinder treat- ment processes in the drug rehabilitation center in Quetta, Pakistan. The findings of the study may help the treatment personnel and the Government to identify problems associated with treatment of drug abusers thus alerting them about possible consequences. Since drug abuse affects the entire society, from the findings, the government may drive policies based on the results of the study which would be supportive to identify how to direct their possible partial resources to uplift the effectiveness of centers.

\section{Literature Review}

The foundation of the detoxification and restoration complex at Eastern By-pass Quetta is In upshot of the activity by the Honorable High Court of Baluchistan, by passing a request in the Constitution Petition (CP) No.181 of 2000. The development work of the complex was finished in February 2009 and it was handed over to the Social Welfare Department, Government of Baluchistan at the start of March being functionalized on 26th March 2009. Without doubt, the foundation of such an establishment is a superb accomplishment and it would be extraordinary not put on record the endeavors made by personnel and gatherings. There has been exceptionally efficient help to higher-ups of the Government of Baluchistan including the commendable Baluchistan Chief Justice, commendable Chief Secretary Baluchistan, the Additional Chief Secretary, and The Finance Secretary, The Social Welfare Secretary, Deputy Social Welfare Secretary and the E.D.O. Community Development.

Treatment for drug addicts varies depending on the activities and strategies used to alleviate symptoms and inducing changes (Jilek, WG, 1994). The types of treatment offered are distinct from their underlying 
philosophies, expected goals, target groups and the context in which they are provided, that is, surgeries or residential.

Many agencies that provide treatment for drug addicts offers two or more treatment modalities. They include detoxification, pharmacological, psychological / counseling and therapeutic interventions. The community also provides rehabilitation services, relapse prevention, and 12 Step post-treatment services (Ashley, M. Jet al.,1995). However, studies have shown that treatment is influenced by the type of drug abuse; the type of program performed; the time period between the start of drug use and treatment.

A study on national treatment in the United Kingdom conducted in the late 1990s on 1,075 patients (UN 2000) showed that people in residential treatment have shown better results to curb heroin abuse than those in outpatient programs.

Amodeo et al., (2006) noted that drug addiction is generally a chronic disease. The disease characterized by relapses and occasional treatments are often not sufficient and no single treatment approach is appropriate for all individuals. Therefore, it is necessary to apply a variety of interventions, since the type of treatment needed is based on the severity of the addiction. A study developed by the Drug Abuse Reporting Program (DARP, 1989) researching 44,000 customers has included 139 programs in the United States in the 1990s. Results indicate improvements in particular regarding heroin. The study also revealed that the longer customers remained the better the results of treatment. Customers who remain in treatment for less than three months, in general, did worse than those who stayed in therapy longer. The dropouts are worse compared to people who have been treated. The commitment at the beginning of the treatment was associ- ated with high stages of abstinence abuse. Therefore, long-term residential treatment programs seemed to get the best results.

A survey conducted by Drug Strategies (2001) revealed that early interventions provide assistance and substantial reduction of drug use. It is also less expensive to do treatments available only after individuals develop addiction. It was also noted that the types of drug abuse tends to vary with age. Bhang and alcohol abuse are the most frequent among customers less than 18 years, while cocaine is associated with older addicts. Although treatment is required as an essential component of the overall drug demand reduction strategy, in the majority of developing countries the number of drug addicts who have access to nursing services is very small, which indicates the need to strengthen and expand treatment infrastructure. It was also stressed that not all drug users seek treatment and those who do tend to do so late in their drug abuse. And, most countries do not have adequate treatment infrastructure which reduces the chances of success (UN 2000).

No previous study has been done to investigate the role of the Detoxification and Rehabilitation Center in Quetta in particular and in Balochistan in general. So the current initial study is conducted to analyse the role of the rehabilitation center and its effects on the reduction of drug addiction in Quetta.

\section{Data Analysis/Results}

The data analysis was carried out on the basis of research questions. Results were discussed on the basis of the main areas of the current study including drug abusers treatment procedures and factors hampering overall treatment. The results of the current study were done on computer by using data analyzing tools. Tables and figures were presented where necessary. 


\section{Professional Qualifications}

The respondents were asked to specify their professional qualifications. $60 \%$ of them had 16 years of education (Masters) in various fields of education; $20 \%$ had 14 years of education (Graduate) and 20\% had 12 years of education (Intermediate). Besides their professional qualification, they had undergone various professional enhancing trainings so that they get well integrated in the Center for better results.

Investigation made by Miller et al. (1976) and Ashery et al. (1985) concluded that treatment for drug addicts depended on skilled professionals. Treatment would follow standard procedures of therapy including confrontation, clarification and eradication of behavior. The best results could only be achieved by professional treatment staffs.

\section{Major Factors Hampering Treatment Process}

The respondents of the study were asked to indicate problems that could hinder treatment of drug addicts in the Centers. They indicated problems like: lack of community support; easily available psychoactive drugs in the society; partial number of drug rehabilitation centers; lack of medicines in the rehabs; lack of doctors; etc. are the key factors that hinder the process of treatment. Therefore, no measurable changes in terms of reduction in the number of drug abuses are seen in the society. Miller et al. (1976) studies showed that anti-abuse, tranquillizers, sedatives, anti-depressants were used in order to withdraw, help and maintain addicts who were willing to stop drug abuse. An addict has various problems so the treatment must focus the individual's, psychological, physical, emotional and social-economic conditions. Mwenesi et al., (1995) studied that readily available psychoactive drugs pose problems as the drug addicts once treated might go back to practice abusing drugs.

\section{Supportive Services for Clients to Enhance the Process of Drug Abuse Rehabilitation}

The respondents were asked to indicate if they offered supportive services and what kind of supportive services to the admitted clients. A variety of supportive services were found to be in practice for enhancing rehabilitation process. These trainings include life skills training; job counseling; skills like shoe making, tailoring, electrical work etc. Being an Islamic state, counseling through religious scholars is a common practice to make the addicts realize and get ready to give up drugs. Amedeo et al. (2006) suggested that supportive services like vocational trainings are very important for successful treatment. Emphasizing strongly on vocational services during residential treatment could prove helpful for clients to overcome barriers to employment.

Perception of Employees on the Nature of Drugs and Treatments Offered:

The current study establishes the perception of the employees on drugs and treatments given to addicts. The respondents were asked if the drugs and treatment given have any influence. Most of the respondents overwhelmingly supported that medicinal drugs used did affect the treatment. Most of the enrolled clients get fully well after the completion of the treatment.

\section{Focus Group Discussions}

An interview was conducted among various family members of drug addicts. The relationship of the participating members with addicts was of brother, uncle and cousin. The aim and purpose of the interview was made clear before to the participants. The participants disclosed that their loved ones are in 
addiction from 1 to 2 years. They consider friend's environment the root cause of drug addiction. They had taken their loved ones for treatment in government and private hospitals but found government hospitals better, more caring and economically favorable as compared to private treatment centers. They added that private hospitals are expensive and lack most basic facilities,. It was further added that the government hospitals had a good system of feedback while the private hospitals had no feedback system. They found the environment of government hospitals supportive and conducive where the behaviors of the staff members were appreciated. Opinion whether the addicts get fully back to their normal life was divided. Some addicts got well and stopped drugs while some went back and started taking/ using narcotics again since they joined their addicted friends again. They suggested that the hospitals must increase their capacity of enrollment and allow the family members to meet their loved once a week. They showed the sign of satisfaction on the performance of the rehabilitation center to which a majority of parents of addicts agreed with outcomes of the rehab center.

\section{The Performance of Rehab}

The data provided by the Administrator of Detox and Rehab as how many patients got enrolled yearly from 2009-2016. The data shows a significant increase in the enrollment of patients in rehab. The data further indicates that the number of drug addicts is increasing in the society which is an alarming situation to both family members and the country. Therefore, a significant en- rollment is seen in the data given below. The data provides strong basis of confidence development on the performance of Detox and Rehab among the performance and drug addicts both, confirming the dedication and commitment of Rehab to bring patients back to normal life.

\begin{tabular}{|c|c|}
\hline Calendar Year & No. Of Patient in the Center \\
\hline 2009 & 91 \\
\hline 2010 & 108 \\
\hline 2011 & 135 \\
\hline 2012 & 150 \\
\hline 2013 & 198 \\
\hline 2014 & 218 \\
\hline 2015 & 251 \\
\hline 2016 & 322 \\
\hline
\end{tabular}

Figure: Performance of Social Welfare Detox and Rehabilitation Center

Figure: Yearly treated patents in social welfare rehabilitation center

\section{Comparison of Detox and Rehab Vs Private Rehab (Milo Shaheed Trust)}

The data (given below) obtained by making a comparison between Detox and Rehab and Milo Shaheed Trust show that both the organizations are treating the drug addicts to a great extent. Milo Shaheed Trust (A nongovernment, non-profitable organization) has been in action since 1989 and is located in the heart of Quetta City and is playing a key role in treating of drug addicts and rehabilitating their lives. Whereas, The Detox and Rehab has been in action since 2009 and located in the outskirts of Quetta (Eastern-by -pass) and getting popularity among the masses for its treating and rehabilitation purposes.

\begin{tabular}{lccccccc}
\hline Year & 2010 & 2011 & 2012 & 2013 & 2014 & 2015 & 2016 \\
\hline Detox and Rehab & 108 & 135 & 150 & 198 & 218 & 251 & 301 \\
\hline Milo Shaheed Trust & 313 & 329 & 311 & 303 & 337 & 350 & 402 \\
\hline
\end{tabular}

Figure: yearly Treated Patients and Detox and Rehab Center with Milo Shaheed Trust

Figure: Compression Chart of Detox and Rehab Center with Milo Shaheed Trust 


\section{Discussion}

Does the use of drugs such as methadone simply replace one drug addiction with another?

No. As used in maintenance, Methadone and LAAM do not replace heroin. They are safe and efficient drugs for opioid dependence that are administered orally in regular and fixed doses. Its pharmacological effects are markedly different from those of heroin. As used in maintenance treatment, Methadone and LAAM are not heroin supplements. "I injected, I smoked, I smoked heroin, I caused an almost instantaneous takeover or a brief period of euphoria that we do not know in a short time, and we signed a 'crash'." The individual then feels an intense desire to consume more heroin to stop the shock and restore euphoria. The cycle of euphoria, shock and desire, which is repeated several times a day, is a cycle of addiction and alteration of behavior. These characteristics of the use of the skin result from the rapid beginning of the drug action and its short duration of action in the support. An individual who uses heroin several times a day subjects his brain and body to be marked, rapid reactions to the flu while the optical effects come and go. These flu shots can alter a significant number of important bodily functions. Because heroin is illegal, people who participate in treatment often become part of a group of people living in the air due to haste and crimes for fitness. Methadone and LAAM have much more gradual action injections than heroin and, as a result, patients stabilized with these drugs do not undergo any alteration. Furthermore, both drugs disappear much more slowly than heroin, so there is no sudden shock and the brain and body are not exposed to the marked fluctuations observed with heroin use. Maintenance treatment with methadone or LAAM significantly reduces the desire for heroin. If a person is held in adequate doses, regular doses of methadone (once a day) or LAAM (several times a week) try to take heroin, the euphoric effects of heroin will be significantly higher. Patients undergoing maintenance therapy do not suffer from medical abnormalities or behavioral destabilization caused by rapid fluctuations in drug stages in heroin addicts.

\section{Role of criminal justice system in the treatment of drug addiction}

Increasingly, research is showing that treatment for drug-addicted offenses during and after hospitalization can have a significant beneficial effect on the future of drug use, criminal behavior and social functioning. The case of integrating therapeutic approaches for drug addiction with the criminal justice system is convincing. Combination treatment based in prison and in the community for treatment reduces the risk of both cancer and criminal behavior and the relapse of drug use. For example, a recent study established that inmates who participated in a treatment program in Delawa State Prison and continued to receive this program on a post-prison work release program, there are $70 \%$ less than anyone else. The participants return to drug use and support rest. Most invoices with the criminal justice system are not in jail, but they are supervised by the community. For people with known drug problems, an additional carpet may be recommended for treatment as a test condition. Research has shown that people who enter treatment under legal pressure have as favorable results as those entering voluntarily (Charles 1999). The criminal justice system makes drug agents who enter therapy through a variety of mechanisms, such as deviating non-violent criminals to treatment; stipulating treatment as a condition of promotion or prevention letting; setting up specialized courts. Who manages cases for drug-related crimes? The drug courts, another model, are dedicated to cases of drug offenses. They mandate and or- 
ganize treatment as an alternative to prison, and monitor progress in treatment and other services for organized criminals involved in the drug. The most efficient models integrate criminal justice and systems for the treatment of risks and services. Treatment personnel and criminal justice work together in implementation of plans and monitoring and supervision, as well as on the systematic use of penalties and rewards for drug addicts in the criminal justice system.

\section{How does pharmacological treatment work to reduce the spread of HIV/AIDS and other infectious diseases?}

Many addicts, such as heroin or cocaine addicts and in particular people who inject drugs are at greater risk for HIV/AIDS and other infectious diseases such as hepatitis C, diseases and sexual infection. For these individuals and the community at large, the treatment of drug addiction is disease prevention. Drug injectors who do not enter treatment are up to six times more likely to be infected with HIV than injectors who enter and remain in treatment. Addicts who enter and continue treatment reduce the activities that can spread diseases, such as sharing syringes and engaging in unprotected sexual activity. Participation in treatments also offer opportunities for evaluation, advice and advice for additional services. The best drug abuse treatment programs provide HIV counseling and offer HIV testing to their patients.

\section{Here are the 12 steps or self-help programs in the treatment of drug addiction}

Self-help groups can integrate and extend the effects of professional treatment. Leading self-help groups are those that are affiliated with Alcoholics, Narcotics Anonymous (NA) and Anonymous Cocaine (CA), who are all based on the 12-step 2021 model for smart recovery. Most drug addiction programs encourage patients to participate in a self-help group during and after formal treatment.

\section{How can families and friends make a difference in the life of someone in need of care?}

Families and friends can play a fundamental role in motivating people with drug problems to enter and stay in care. Family therapy is important, especially for adolescents. The participation of a family member in a person's treatment program can strengthen and extend the benefits of the program.

\section{Is the treatment of drug addiction worth its cost?}

The treatment of drug dependency is profitable in relation to drug use and related social and health costs. Treatment is less expensive than alternatives, not to mention drug addict's relief. For example, the average cost of a full year of methadone maintenance treatment is about $\$ 4,700$ per patient, while a full year of incarceration costs about $\$ 18,400$ per person. The treatment of drug addiction is a reduction in drug use and related social and health costs. According to various conservative estimates, every $\$ 1$ invested in drug addiction treatment programs yields between $\$ 4$ and $\$ 7$ in reducing drug-related crime, criminal justice costs and theft alone. When health care savings are included, total savings can outweigh the costs at a 12 to 1 ratio. Major savings for the individual and society also result from significant declines in interpersonal conflicts, productivity improvements in the workplace and reductions in drug-related accidents.

Drugs are substances (solid, liquid or gas), that when consumed, breathed in, injected, smoked, absorbed through and reinforced may bring physiological alterations to normal body functions. "Drug abuse" is 
defined to be self-administration of a drug in frequently significant quantities that may hamper an individual's ability to perform life activities efficiently and which may prove to be socially, physically, or emotionally harmful.

Addiction of any drug is referred to be a serious problem that badly affects the brain and behavior of an individual. The drugs change normal brain physiology creating so called better feelings of happiness, shortlived, and tend to have long-standing side effects on brain physiology and its performance (Donaghy, ME, 1997). Drug addiction is considered a serious, long-lasting, health worsening issue irrespective of sex, background or age of drug addicts. Nevertheless, it can be treated. Drug addiction goes on in some expected stages. Addicts feel the urge of craving and use drugs often, failing to quit by self-efforts. It is therefore, necessary to provide timely support and reasonable treatment to eradicate this fast-growing problem. Drug Rehabilitation Complexes therefore, become so important in the formation of drug addict free society (Broome, 1998).

Drug dependency (addiction) is generally a habit of daily consumption of drugs without which an individual can no longer stay comfortable and cannot do life activities. If drug intakes stop that may likely produce unwanted symptoms like vomiting, shaking of body, itching in bones, joint pain, diarrhea etc.

As in other parts of the country, Quetta is also facing the narcotics problem. Therefore, in Quetta three rehabilitation centers are functioning. Especially, the Government of Balochistan Social Welfare Rehabilitation Center is playing a vital role in this regard, the Rehabilitation Center is giving free treatment; teaching them different skills (i.e. making shoes, using computer, tailor- ing, educating; developing religious values; taking them towards sports; etc.

\section{Conclusion}

Results of the present study revealed that easily available psychoactive drugs in society; partial number of drug rehabilitation centers; lack of medicines in the rehabsl lack of doctors; etc. are key factors that hinder the process of treatment. Therefore, no measurable changes in terms of reduction in the number of drug abuses are seen in the society. A variety of supportive services were found to be in practice for enhancing rehabilitation processes. These trainings include life skills training; job counseling; skills like shoe making, tailoring, electrical work; etc. Being an Islamic State, counseling through religious scholars is a common practice to make the addicts realize and get ready to give up the drugs. Most of the respondents overwhelmingly supported that drugs used did affect the treatment. Most of the enrolled clients get fully well after the completion of the treatment. It was established that the Government Hospitals had good systems of feedback while the environment of Government Hospitals was supportive and conducive where the behaviors of the staff members were appreciated. The present study showed a signifi-cant increase in the enrollment of patients in rehab confirming the dedication, commitment and remarkable performance of Rehab to bring back the patients to the normal life.

The Detoxification and Rehabilitation Complex has been functioning since 2009 and located in the outskirts of Quetta (Eastern-by-pass) gaining popularity among the masses for its treatment and rehabilitation support playing a central role in the reduction of drug addicts in society.

Narcotics have become a global problem and have assumed to be a progressively serious issue internationally. So based on the 
current study the following recommendations are suggested.

\section{Recommendations}

From the research findings the following recommendations were made:

There must be a clear policy to standardize the treatment measurements to certify that they are comprehensive and result bearing.

The Ministry of Health through the Government must give subsidy in the cost of treatment to the drug abusers.

The Ministry of health must make sure of the timely supply of medicines to drug rehabilitation centers.

Treatment Centers must ensure training of treatment personnel so that they become fully aware of the environment and nature of addicts.

The Government must increase the number of drug rehabilitation centers.

The Government must add some chapters regarding various forms of narcotics and their side effects and conduct seminars in the educational institutions to alert the young generation.

\section{References}

1. ALTAF A, SHAH S A, ZAIDI $\mathrm{N}$ A, MEMON A, WRAY N (2007). High risk behaviors of injection drug users registered with harm reduction program in Karachi, Pakistan. Harm Reduction Journal, 4(1), 7.

2. ASHLEY M J, BULL S B, PEDERSON LL (1995) Support among smokers and nonsmokers for restrictions on smoking. American journal of preventive medicine, 11(5), 283-287.

3. DONAGHY M E (1997) The investigation of exercise as an adjunct to the treatment and rehabilitation of the problem drinker (Doctoral Dissertation, University of Glasgow).

4. DRUG ABUSE REPORTING PROGRAM ( 1989 ) h t t p s : / / w w w.g o o g l e. com.pk/search?biw $=1352 \&$ bi $\mathrm{h}=591 \& \mathrm{ei}=$ BAEtXJWuIcmi1fAPhsSoqAQ\&q=drug+abuse+reporting + program $+1989 \&$ oq $=d r u g+a b u s e+r e-$ porting+program $+1989 \&$ gs_1=psy...61977.63636..64244...0.0..0.321.1453.23 j 2 . . . . . . . 0 . . . . 1 . . gws-wiz......0i22i30j33i22i29i30j33i160. FPpsv3JQeUM.

5. GIANNICO S, HAMMAD F, AMODEO A, MICHIELON G, DRAGO F, TURCHETTA A, SANDERS SP (2006) Clinical outcome of 193 extracardiac Fontan patients: the first 15 years. Journal of the American College of Cardiology, 47(10), 2065-2073. http:/www.nationaldrugstrategy.gov.au/internet/drugstrategy/Publishing.nsf/content/ alc-strategy(2001).

6. IVERSEN LL, ROGAWSKI MA, MILLER, RJ (1976) Comparison of the effects of neuroleptic drugs on pre-and postsynaptic dopaminergic mechanisms in the rat striatum. Molecular pharmacology, 12(2), 251262.

7. JILEK WG (1994) Traditional healing in the prevention and treatment of alcohol and drug abuse. Transcultural Psychiatric Research Review, 31(3), 219-258.

8. MALLINSON J, COLLINS I (2012) Macrocycles in new drug discovery. Future medicinal chemistry, 4(11), 1409-1438.

9. MWENESI H, HARPHAM T, SNOW RW (1995) Child malaria treatment practices among mothers in Kenya. Social Science \& Medicine, 40(9), 1271-1277.

10. RAY, OKSIR, CHARLES (1999) Drugs, Society, and Human Behavior.

11. SIMPSON D, BROOME KM (1998) Effects of readiness for drug abuse treatment on client retention and assessment of process. Addiction, 93(8), 1177-1190.

12. WHITE, WL (1998) Slaying the dragon: The history of addiction treatment and recovery in America (p. xvi). Bloomington, IL: Chestnut Health Systems/Lighthouse Institute. 